Revue bibliographique pour le domaine irano-aryen

\title{
Eberhard Sauer, Hamid Omrani-Rekavandi, Jebrail Nokandeh, Tony Wilkinson. Die sasanidischen Grenzwälle im Nord-Iran
}

\section{Rémy Boucharlat}

\section{(2) OpenEdition \\ 1 Journals}

\section{Édition électronique}

URL : http://journals.openedition.org/abstractairanica/40574

DOI : 10.4000/abstractairanica.40574

ISSN : 1961-960X

Éditeur :

CNRS (UMR 7528 Mondes iraniens et indiens), Éditions de l'IFRI

\section{Édition imprimée}

Date de publication : 1 décembre 2013

ISSN : 0240-8910

Référence électronique

Rémy Boucharlat, «Eberhard Sauer, Hamid Omrani-Rekavandi, Jebrail Nokandeh, Tony Wilkinson. Die sasanidischen Grenzwälle im Nord-Iran », Abstracta Iranica [En ligne], Volume 32-33 | 2013, document 200, mis en ligne le 01 juillet 2016, consulté le 29 septembre 2020. URL : http://

journals.openedition.org/abstractairanica/40574 ; DOI : https://doi.org/10.4000/abstractairanica. 40574

Ce document a été généré automatiquement le 29 septembre 2020.

Tous droits réservés 


\title{
Eberhard Sauer, Hamid Omrani- Rekavandi, Jebrail Nokandeh, Tony Wilkinson. Die sasanidischen Grenzwälle im Nord-Iran
}

\author{
Rémy Boucharlat
}

\section{RÉFÉRENCE}

Eberhard Sauer, Hamid Omrani-Rekavandi, Jebrail Nokandeh, Tony Wilkinson. « Die sasanidischen Grenzwälle im Nord-Iran », in : A. Nunn, Hrsg., Mauern als Grenzen. Mainz, von Zabern, 2009, p. 127-143.

Commode résumé des résultats des recherches de la mission irano-britannique qui, depuis 2005, a amplifié les travaux iraniens précédents sur le fameux «Mur d'Alexandre » (cf. Abs. Ir. 29, c.r. $n^{\circ} 125$; Abs. Ir. 30, c.r. $n^{\circ}$ 117). La mission a obtenu des résultats importants sur la date, maintenant mieux assurée aux $\mathrm{V}^{\mathrm{e}}-\mathrm{VI}^{\mathrm{e}}$ s. d.n.ère, sur la structure et l'organisation de cette ligne de défense et des monuments associés (forts à intervalles assez réguliers, tours, fours à briques très nombreux, locaux de stockage, etc.). Ainsi constitué, le mur pouvait héberger jusqu'à 30000 soldats en tant de crise, mais les effectifs devaient être faibles en temps de paix. 


\section{AUTEURS}

RÉMY BOUCHARLAT

CNRS, Lyon 